\title{
Study on the Influence for Hybrid Electric Vehicle Performance by the Thermal Effects of Traction Motor
}

\author{
Wei Wang Renguang Wang Yongjun Tian \\ Automotive Engineering Research Institute \\ China Automobile Technology and Research Centre \\ Tianjin, China \\ Wangwei2011@catarc.ac.cn
}

\begin{abstract}
Keywords: Thermal effects, Traction motor Simulation, Parallel electric Vehicle
Abstract:According to the base theory of heat transfer, a thermodynamic for the permanent synchronous motor of hybrid electric vehicle was studied. The conception of temperature modulation factor was introduced; the temperature raise impacting the fundamental characteristics for motor was analyzed. Then the thermodynamic model of permanent magnetism synchronous machine was build in the vehicle simulation analyze platform in ADVISOR, the motor efficiency module and torque module were modified. Take HWFET and Beijing drive cycle for example, a parallel hybrid electric vehicle with the modified motor model and the motor model in the ADVISOR which was not modified were simulated and compared each other. The results proved that the actual performances of motor can be reflected further by the motor model which considering the thermal effects. So the simulation precision of model for hybrid electric vehicle can be improved.
\end{abstract}

\section{Introduction}

The traction motors of hybrid electric vehicle were different from industry motors, and major differences were the con With the development of the machinery manufacturing technology and automation control technology, direct current motor, induction motor, permanent magnet motor and switch reluctance motor, can be used as the electric vehicle traction motor ${ }^{[1,2]}$. According to the operation environment and characteristic of electric vehicle, the traction motor must satisfy the following specification:(1)high power and torque density (2) wider range of speed and higher efficiency (3)reliability(4)lower cost.

The temperature raise as an important evaluation index of traction motor will effect the output power and efficiency, torque directly. In addition, when the motor temperature raise or exceed motor maximum temperature suddenly, the motor malfunction will happen. In the document for both at home and abroad, the motor temperature model was ignored in the HEV model.

Even if the motor temperature model was build, motor basic characteristic index varied with motor temperature change was not analysed. Relative to ordinary motor, the permanent magnetism motor was more sensitivity to temperature because material performance. if the motor basic characteristic effect with temperature raise was not considered ${ }^{[3]}$, the simulation operation was more difference with motor actual characteristic. Permanent magnetism motor thermodynamic model taking into account of temperature raise was build with Matlab/Simulink in simulation platform, then the simulation result was improved.

\section{parallel hybride ecletric vehicle basic structure}

A parallel hybrid electric bus was made of single clutch and mechanical type automatic transmission, engine ,motor and torque synthesizer assembly. 
Except for motor, battery and assistance unit, the structure was similarly to vehicle as shown in the fig 1.

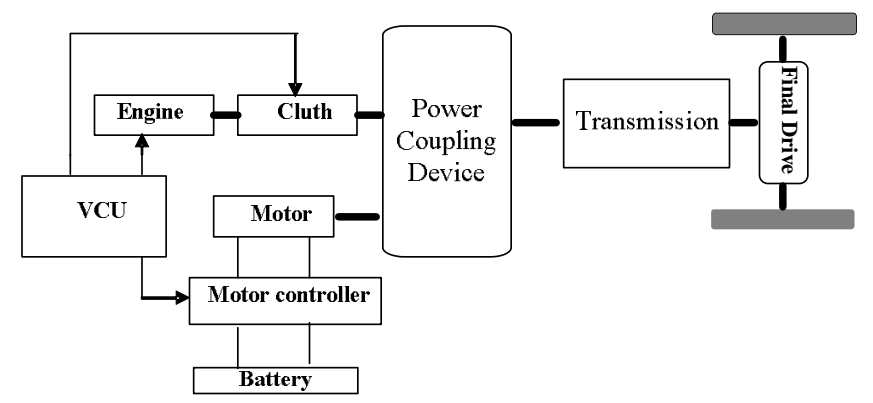

Figure. 1 The configuration of a double axle parallel hybrid electric vehicle

\section{TRACTION motor thermodynamic analysis}

Because the power for traction motor of hybrid electric vehicle was high, the heat interior motor will be produced. The heat was made up of copper loss, iron loss and other extra loss, the emit way was shown in the fig2.

The heat generated by the motor generally transmit from heating unit interior to heating unit surface, then the heat was disperse to environmental by the way for convection and radiation effect. According to three heat transfer mode for conduct and convection, radiation, find calculation method for traction motor temperature raise.

Motor loss temperature calculation was major with reduction formula in the temperature field calculation ${ }^{[4,5]}$. The heat dissipating capacity in different kinds of way was derived in the following article.

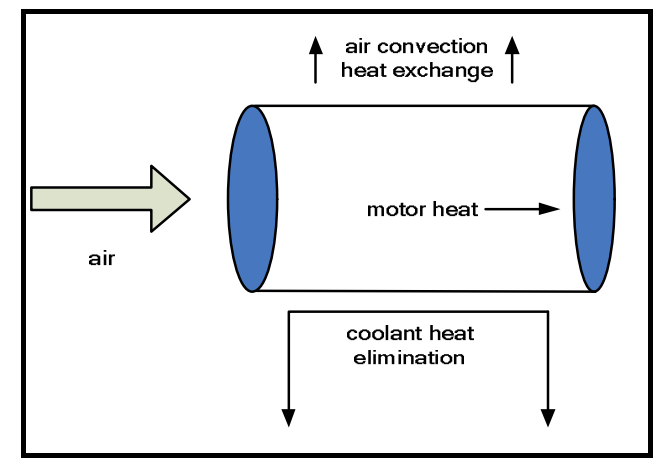

Figure.2 Schematic of motor thermal model

\section{A. Air convection heat exchange}

The heat convection was made up of two ways for energy exchange by the mol random motion and fluid bulk movement. The heat was produced by the traction motor will be transferred by the natural convection and forced convection. According to Newton's law, the heat by the convection radiating was proportional to the solid or fluid temperature difference and area of dissipation. So the heat was transferred by the air could be calculated by the formulae:

$$
Q_{\text {air }}=h_{\text {air }} A\left(T_{m c}-T_{\text {ambient }}\right)
$$

$h_{\text {air }}$ - air heat transmission coefficient;A-motor surface area;

$T_{m c}$ - motor temperature; $T_{\text {ambient }}$ - ambient temperature.

Not only air heat transmission coefficient was related with boundary layer status, but also was determined by geometry of shell of pipe, fluid kinetic characteristic, thermodynamic property, cooling 
medium characteristic. Therefore the air heat transmission coefficient can be determined according to the empirical formula in the document, the natural convection air transmission coefficient was determined by the criteria equation.

$$
N \mu_{L}=\frac{h L}{K}=0.52 \times\left(\frac{\beta \Delta T g L^{3}}{v a}\right)^{0.25}
$$

$\frac{\beta \Delta T g L^{3}}{v a}-$ grash of number; $N \mu_{L}$-nusselt number; $h \propto \Delta T^{0.25}$;

air forced-convection heat transfer coefficient can be calculated by the formulae(3)

$$
\begin{aligned}
& N \mu_{L}=\frac{h L}{K}=0.19 \times\left(R_{e}\right)^{0.63}\left(P_{r}\right)^{0.36} \\
& R_{e}=\frac{V L}{v}, P_{r}=\frac{v}{\partial}
\end{aligned}
$$

$R_{e}$ - Reynolds number; $P_{r}$ - Prandtl number; $h \propto V^{0.36}$

According to experimental data air convection heat exchange thermal transmissive was $6 \mathrm{w} / \mathrm{m}^{2}$, air rate $48.27 \mathrm{~km} / \mathrm{h}$, forced convection coefficient was $60 \mathrm{w} / \mathrm{m}^{2}{ }^{\circ} \mathrm{C}$. air convection heat exchange initial value was supposed for $6 \mathrm{w} / \mathrm{m}^{2} .{ }^{\circ} \mathrm{C}$.If the temperature raise was $1000^{\circ} \mathrm{C}$, the formula can be derived.

$$
h_{\text {air }}=6+6 \times\left(\frac{\Delta T}{1000}\right)^{0.25}+60 \times\left(\frac{V_{\text {air }}}{48.27}\right)^{0.63}
$$

\section{B. The heat for coolant heat convection}

The traction motor cooling system was made up of water tank and radiator, motor. Because the length of water pipe between motor and water tank was short, so the heat elimination for water pipe can be ignored. The heat transfer process for coolant and motor surface was forced-convection heat transfer, so the computing formula was derived.

$$
Q_{\text {coolant }}=h_{\text {water }} A\left(T_{m c}-T_{\text {water }}\right)
$$

\section{$h_{\text {water }}$ - coolant average coefficient of thermal transmission; $T_{m c} \longrightarrow$ motor temperature;}

With regard to coefficient of heat transfer for cooling water, it was determined by different water velocity and flow. In the research process, the coolant can be restored to initial temperature if the radiator was perfectly. The coefficient of heat transfer of coolant can be selected mean value.

\section{The heat for coolant heat convection}

Heat radiation was the radioactive energy object was in the temperature. The radiation may be happened in the solid surface, but liquid and gas can emit energy. No matter sort object, the heat radiation was generated by the atom or molecular electronic arrangements consist of object varied. The radiation dispersion heat by the traction motor can be determined by stephanian- Bohr betel graceful law.

$$
Q_{\text {rad }}=\eta \sigma A\left(T_{m c}^{4}-T_{\text {ambient }}{ }^{4}\right)
$$

- stephanian

- Bohr betel graceful constant,take the value $5.67 \times 10 \times 10^{-8}$; radiation factor TAKEN value 0.9. $\sigma$ - stephanian, the value was $5.67 \times 10^{-8} ; \eta$ —radiation, the value was 0.9 .

After the heat capacity was calculated, the motor temperature can be derived by the formulae ${ }^{[7]}$

$$
T_{m c}=\int_{0}^{t} \frac{Q_{m c_{\text {_gen }}}-Q_{\text {air }}-Q_{\text {rad }}-Q_{\text {coolant }}}{m_{m c} \times c_{p m c}} d t
$$


$Q_{m c_{-} g e n}$-motor total heat $m_{m c}$-motor quality; ${ }^{c_{p m c}}$-motor specific heat capacity.

There was a salient feature was that traction motor may be have a bigger overload factor, so the motor driving torque can be satisfied with the requirement that the vehicle climbing and overtaking. With regard to the hybrid electric vehicle traction motor, the motor may be continuous work $30 \mathrm{~s}$ in certain cooling conditions. The traction motor for EV must be operated with peak torque at least $3 \mathrm{~min}$.

\section{Temperature rAise effect motor performance}

HEV traction motor can be continuous operated with rated torque. When the motor operated in the overload region, the runtime for motor can be limited. Furthermore with the motor temperature varied, the torque may be changed. For permanent magnetism synchrony motor, permanent material including neodymium iron boron permanent magnetism and ferrite permanent magnetism was very sensibility with temperature. If the motor operated from cold state to thermal state, the temperature raise $100^{\circ} \mathrm{C}$, the airgap flux per pole for neodymium iron boron permanent motor and ferrite permanent motor will reduce about 12 . $6 \%$ and $18 \% \sim 20 \%$ separately. The operating characteristic for permanent motor will be affected particularly.

The permanent magnetism motor for prius was thermodynamics tested in America oak national laboratory ,the test result indicated when the winding temperature was $92.9^{\circ} \mathrm{C}$, motor peak torque was $320 \mathrm{~N}$.m. When winding temperature was $70.8^{\circ} \mathrm{C}$, motor peak torque was $344 \mathrm{~N} . \mathrm{m}^{\text {[8 }}$.

\section{A. Air convection heat exchange}

The motor steady state torque performance contour curve in the vehicle simulation model was shown in the fig3.According to reference [9], if the temperature raise was considered, the motor maximum torque will be varied with the thermal get together, not the curve in the fig3.

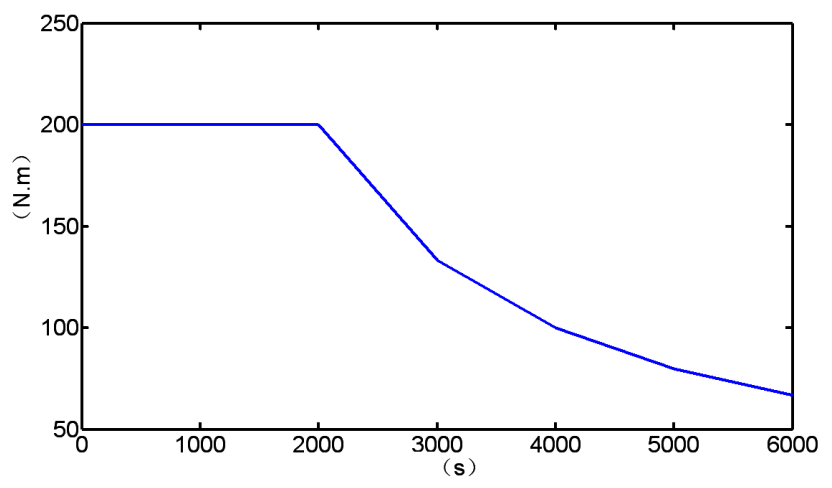

Figure3.The mechanical characteristics curve for traction motor

In order to explaining clearly the relation between motor temperature raise and maximum torque, the paper proposal temperature modulation factor concept. The effect between motor temperature and maximum torque can be derived by the formula ${ }^{[10]}$. The motor peak torque can be deduced by the formula.

$$
T_{\max }=T_{\text {cont }} \times P W M_{\text {heat_index }}+T_{\text {peak }}\left(1-P W M_{\text {heat_index }}\right)(8)
$$

$P W M_{\text {heat } \_ \text {index }}$ - temperature modulation factor; $T_{\text {cont }}$-motor rated torque; $T_{\text {peak }}$-motor peak torque. $^{P W M_{\text {heat_index }}}$ value was between 0 and1. When $P W M_{\text {heat_index }}=0$, the motor was in cold state, $T_{\max }=$ $T_{\text {peak }}$; when $P W M_{\text {heat } \_ \text {index }}=1$, The motor peak torque was equal to motor rated torque.So, the motor peak torque will be changed with $P W M_{\text {heat_index }}$. Temperature modulation factor may be expressed: 
$P W M_{\text {heat_index }}=-P W M_{\text {intial_index }}+\int_{0}^{t} \frac{T_{\text {gain }}}{T_{s}}\left(\left|\frac{T_{\text {out }}}{T_{\text {cont }}}\right|-1\right) d t$

$T_{\text {out }}$ - the motor actual output torque; ${ }^{T_{s}}$ — The most long runtime for motor peak torque; ${ }^{T_{\text {gain }}}$ — torque along with temperature rate of change; $P W M_{\text {intial_index — }}$-temperature modulation factor initial value, ${ }^{t}$ motor run time.

$$
T_{\text {gain }}=f\left(T_{m c}, t\right)
$$

$T_{\text {gain }}$ was motor working hours and temperature function, which was determined according to temperature raise test; $P W M_{\text {intial_index }}$ was relatively in response to motor runtime,indicate the time for motor torque was not effected by temperature influence, which was relate to motor initial temperature. For example, Take $T s=30, T_{\text {gain }}=0.3, P W M_{\text {intial_index }}=0.3$;

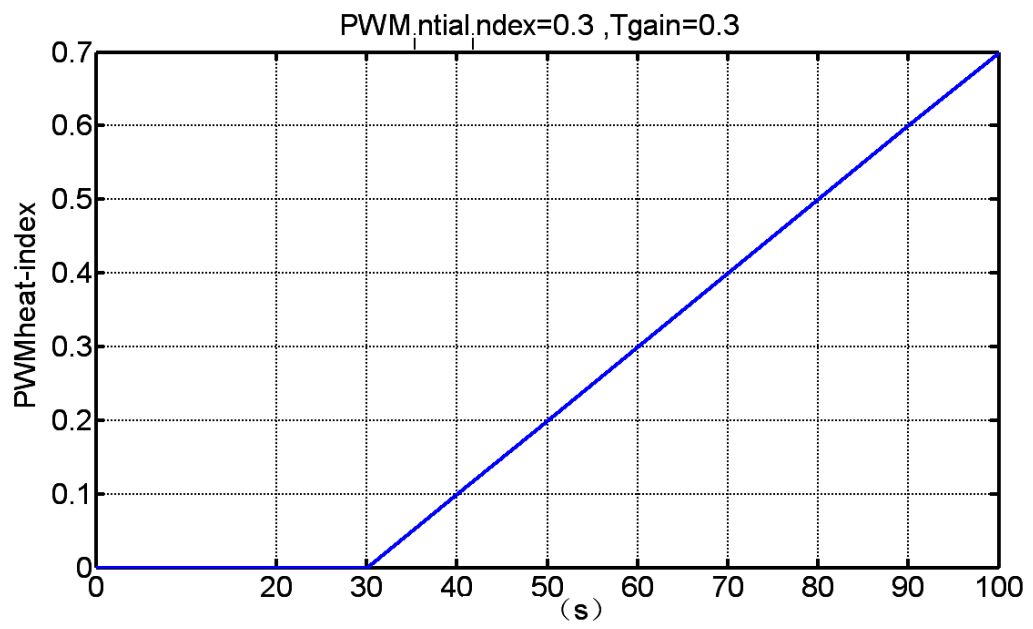

Figure 4. Temperature modulation factor curve for traction motor

The motor operated continuous with two times rated torque, so the temperature modulation factor varied diagram can be derived. With regard to different type motor, the $P W M_{\text {intial_index }}$ and $T_{\text {gain }}$ valu can change motor performance and sensitivity toward to the temperature.

B. Temperature rise effect traction motor efficiency

$\eta=\frac{P_{\text {out }}}{U I}=\frac{c_{e} n K A_{m} B r\left\{\left(1-\frac{I L}{100}\right)\left[1-\frac{\partial_{B r}}{100}\left(t-t_{0}\right)\right]\right\}}{U I}$

$t_{\text {-motor temperature; }}{ }^{t_{0}}{ }_{\text {- motor initial temperature; }}{ }{ }_{B r}$ - temperature coefficient (constant within temperature rise range); $I L$ _ inconvertibility loss rate; $A_{m}$ — permanent magnet supply per pole flux sectional area; $\mathrm{Br}$-residual magnetic flux density in the room temperature( $\mathrm{T}), c_{e}$-electromotance constant;n-motor speed; $U$-motor voltage; $I$-motor current

When the input voltage and current did not change, the motor temperature will increase and magnetic induction will be reduced. So the motor efficiency will reduced with the temperature increasing. In the document [10], the result indicated the efficiency of permanent magnetism synchrony motor will decrease $2 \sim 3 \%$ in the temperature raise range. 


\section{Modeling and simulation}

The simulation model of Par hybrid electric vehicle and motor thermodynamic model will be built in the ADVISOR platform. As was shown in the fig5 and fig6, the traction motor fundamental performance parameter in the table 1.

When the motor temperature was greater than the $35^{\circ} \mathrm{C}$, the cooling water was opened in the vehicle model. When the motor maximum temperature exceeded $70^{\circ} \mathrm{C}$,the motor stop operate. When the motor temperature exceed $35^{\circ} \mathrm{C}$, the torque and efficiency rectified module came into action. Take the value for Ts $=30, P W M_{\text {intial } \_ \text {index }}=0.3$, the will be between the 0.1 and 0.3 with the motor temperature varied. Take the coolant convection heat transfer coefficient value for $3000 \mathrm{w} / \mathrm{m}^{2}{ }^{\circ} \mathrm{C}$, the motor initial temperature was $20^{\circ} \mathrm{C}$ and ambient temperature was $20^{\circ} \mathrm{C}$. The motor efficiency will decrease one percentage point when the motor temperature increase $15^{\circ} \mathrm{C}$. In addition, the motor power loss was taken into account in model(noise, friction loss), the loss was occupied for 5\%.

The HWFET and Beijing vehicle cycle condition were taken for simulation test. The vehicle speed was required highly in the HWFET cycle, the motor temperature and temperature modulation factor varied curve in HWFET cycle was shown in the fig7 and fig 8.the temperature modulation factor gradually increase from the $387 \mathrm{~s}$ with the motor temperature increasing, the maxima value was 0.35.Because the function for coolant, the temperature modulation factor will be gradually to 0 in the

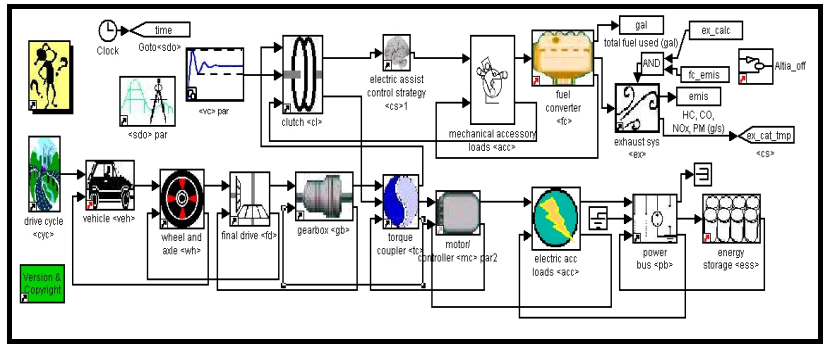

Figure 5.The simulation model for vehicle

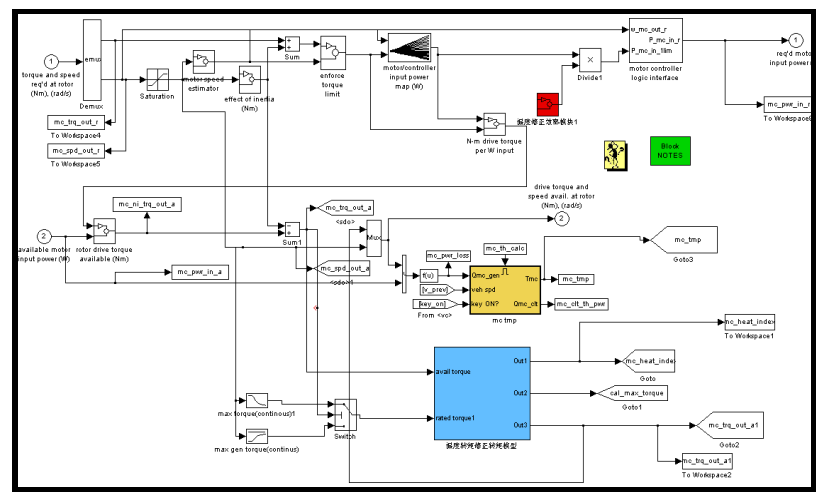

Figure 6.The modified motor temperature model 
Table 1 The basic parameters for traction motor

\begin{tabular}{c|c}
\hline motor style & $\begin{array}{c}\text { water-cooling, three phase permanent magnetism } \\
\text { synchro motor }\end{array}$ \\
\hline basic speed/ maximum speed $(\mathrm{rpm})$ & $3600 / 6000$ \\
\hline rated power / peak power(Kw) & $90 / 30$ \\
\hline peak torque(N.m) & 240 \\
\hline temperature rise limit & 125 \\
\hline cooling area(m2) & 0.4273 \\
\hline specific heat capacity $/ \mathrm{Kg}^{\circ} \mathrm{C}$ & 430 \\
\hline quality $(\mathrm{kg})$ & 100 \\
\hline
\end{tabular}

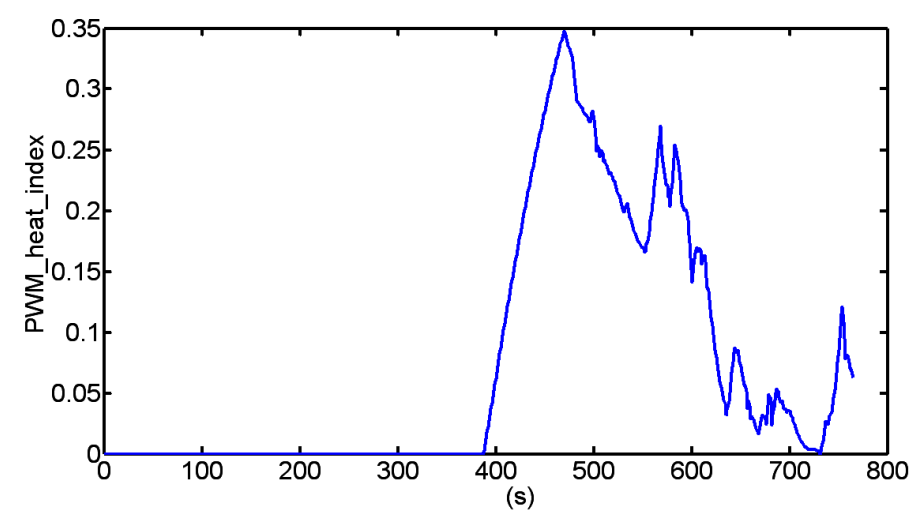

Figure 7. Temperature modulation factor curve in UDDS drive cycle

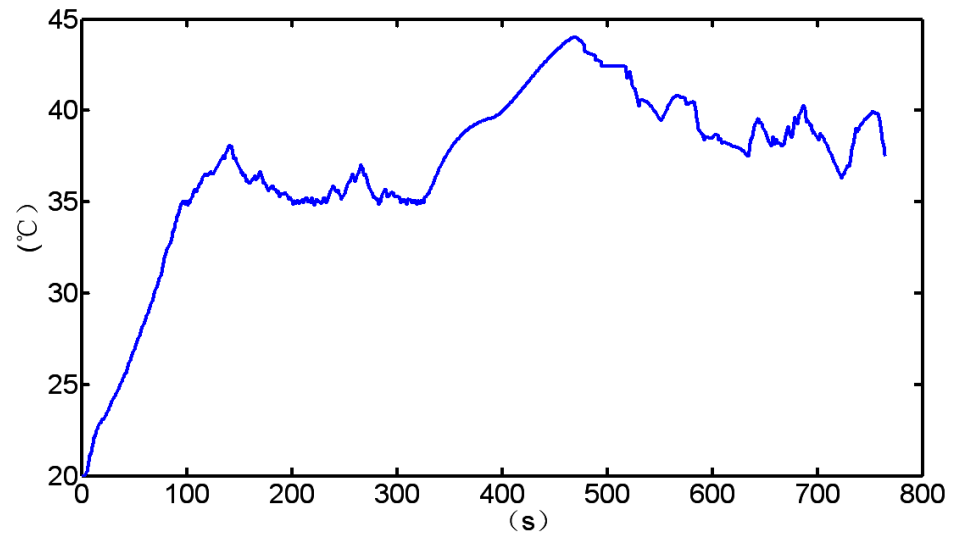

Figure 8.Temperature curve in UDDS drive cycle 


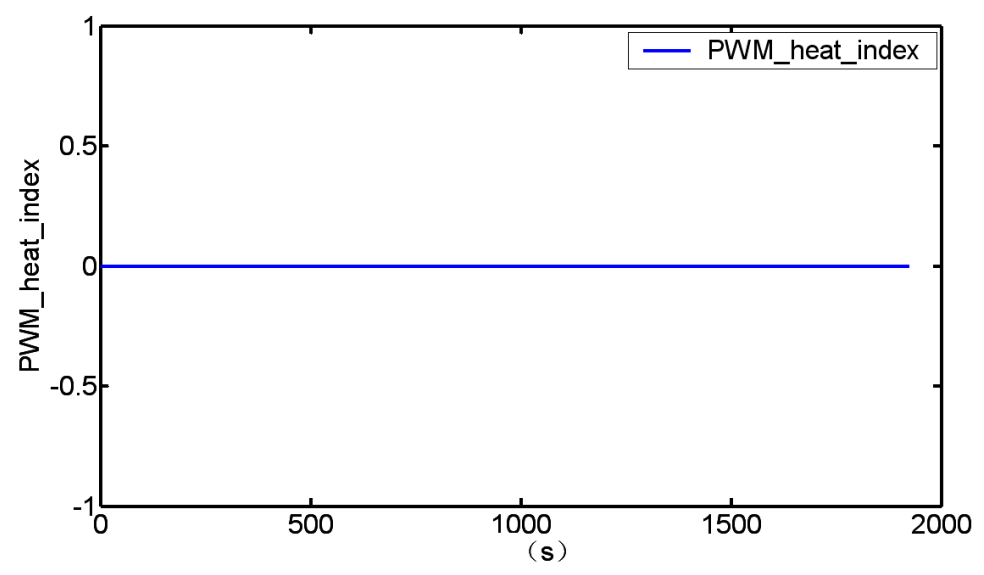

Figure 9.Temperature modulation factor curve in Beijing drive cycle

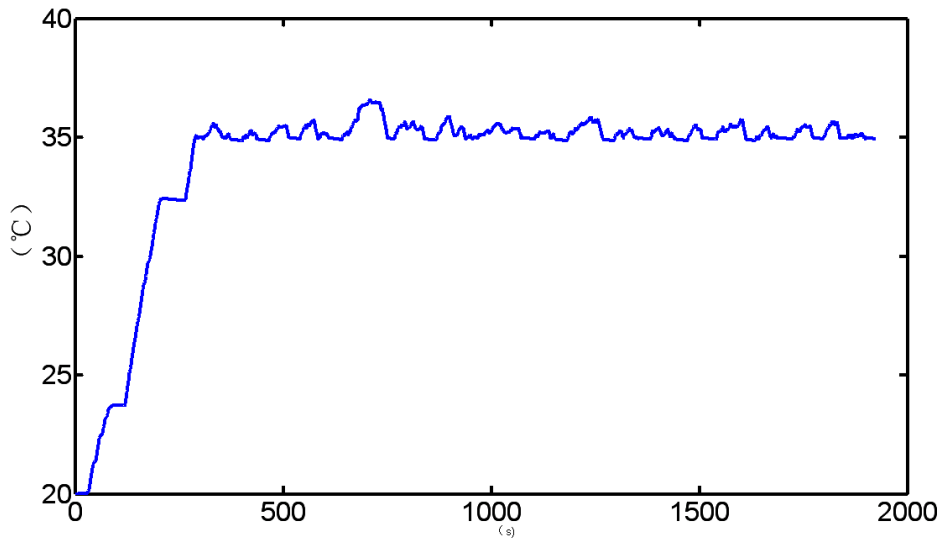

Figure 10.Temperature curve in Beijing drive cycle

succeed 300s.the motor maximum temperature will be $44^{\circ} \mathrm{C}$, ultimately the temperature will be fluctuate wave at $37.5^{\circ} \mathrm{C}$.

As was shown in the fig 9 and fig 10 , the motor temperature and temperature modulation factor varied curve in the Beijing cycle. the motor operating point operated in the rated torque region in the beijing cycle, only little operating point was in the motor overload region. The motor temperature began to rise up to $35^{\circ} \mathrm{C}$ from initial temperature, the cooling water model will be opened. Because the motor hardly operated in the overload region, the motor temperature will be fluctuate waved at $35^{\circ} \mathrm{C}$. So the motor temperature modulation factor value was 0 , the motor peak torque was not effected by the motor temperature.

The vehicle economy simulation comparative results in the table 3 between motor model and motor temperature model rectified. In the HWFET cycle , the oil consumption in hundred kilometres was decrease $0.3 \mathrm{~L}$.Because the time for motor continuous operate continuously was less in the parallel electric vehicle, runtime for motor operating only occupied for $30 \%$.In the beijing cycle, the motor operate in good conditions and hardly in the overload region, So the fuel economy was not effected. 
Table2 . The simulation result of fuel economy for two type motor model

\begin{tabular}{|c|c|c|c|}
\hline $\begin{array}{c}\text { Driving } \\
\text { cycle }\end{array}$ & Performance index & $\begin{array}{c}\text { Without thermometric corrction } \\
\text { model }\end{array}$ & $\begin{array}{c}\text { The thermometric corrction } \\
\text { model }\end{array}$ \\
\hline UDDS & $\begin{array}{c}\text { hundred kilometer oil } \\
\text { consumption(L) }\end{array}$ & 35.3 & 35.6 \\
\hline Beijing & $\begin{array}{c}\text { hundred kilometer oil } \\
\text { consumption(L) }\end{array}$ & 27.1 & 27.1 \\
\hline
\end{tabular}

Table3. The simulation result of power performance for two type motor models

\begin{tabular}{|l|l|l|l|}
\hline Performance index & $\begin{array}{l}\text { Without thermometric } \\
\text { correction model }\end{array}$ & $\begin{array}{l}\text { Motor initial temperature } 30^{\circ} \mathrm{C} \\
\text { in motor revise model }\end{array}$ & $\begin{array}{l}\text { Motor initial temperature } 50^{\circ} \mathrm{C} \\
\text { in motor revise model }\end{array}$ \\
\hline Maxima speed(km/h) & 89 & 89 & 89 \\
\hline $\begin{array}{l}0-60 \mathrm{~km} / \mathrm{h} \\
\text { acceleration time }(\mathrm{s})\end{array}$ & 16.4 & 16.8 & 17.1 \\
\hline $\begin{array}{l}4 \% \text { gradient running } \\
\text { speed }\end{array}$ & 48.3 & 48.3 & 48.3 \\
\hline
\end{tabular}

Generally the acceleration time for vehicle for $0-60 \mathrm{~km} / \mathrm{h}$ was less than $30 \mathrm{~s}$, the motor temperature was not changed. So the single cycle can not reflect the effect for temperature raise to vehicle dynamics. In order to reflect motor temperature raise in the model, the motor initial temperature was set to $35^{\circ} \mathrm{C}$ and $50^{\circ} \mathrm{C}$ separately and the coolant closed. The two motor model dynamics character simulation contrast result was in the table 3 .the time for acceleration in the $0-60 \mathrm{~km} / \mathrm{h}$ will be increase with the motor initial temperature increasing in the motor temperature model; the climbing degree and maxima vehicle speed were not changed.

\section{Conclusions}

According to the temperature sensibility characteristic for permanent magnetism synchro motor in this paper, the motor performance effect by the traction motor heat elimination mechanics and motor temperature raise was analysed. The conclusion can be derived in the vehicle cycle simulation:

1)The motor thermodynamic model which have consider temperature raise influencing can simulate the motor real operation status, and the model simulation precision for HEV can be improved.

2) If the motor often operated in the overload region, the motor temperature raise will increasing quickly, so the vehicle dynamics and economy will be fallen.

3) The motor initial temperature and cooling system will affect the motor performance.

\section{Acknowledgment}

The author would like to thank China Automobile Technology and Research Centre for their support of this work. And this project is supported by National Hi-tech Research and Development Program of China (863 Program, Grant No. 2011AA11A211).

\section{References}

[1] C.C.Chan,Choubin, xie qicheng. fuel cell electromobile [M]. Beijing:tsinghua university publisher,2005.

[2] E.Hall,M.S.S Ramamaurthy, J.C.Balda. Optimum Speed Ratio of Induction Motor Drivers for 
Electric Vehicle Propulsion[J] Proceedings of the 2001 Applied Power Eletrical conference,pp.371377, Anaheim,California,March 2001.

[3] Daiki Tanaka, Takashi Kato, Yuichi Shibukawa, Yuji Naruseand Tadayuki Hatsuda. Study on a High Torque Density Motor for an Electric Traction Vehicle[J].SAE TECHNICAL PAPER, 2000-011337.

[4] M.Anxo Prieto Alonso, X. M. LdpezbFernbndez, Manuel Perez Donsidn. Harmonic.Effects on Rise of A Squirrel Cage Induction Motor. [J] ICEM 2000.EspooFinland:Helsinki University of Technology, 2000:144-147.

[5] M. Shanel,S.J Pickering, D. Lampard. Application of Computational Fluid Dynamicsto the Cooling of Salient Electrical Machines.[J] ICEM 2000. EspooFinland:Helsinki University of Technology,2000:338-342.

[6] Aaron Brooker, Kristina Haraldsson, Terry Hendricks, Valerie Johnson, Kenneth Kelly, Bill Kramer. ADVISOR Help Document. National Renewable Energy Laboratory,2002

[7] Bai feng-liang. Yangjian-guo.Modeling of Motor in Hybrid Electric Vehicles. Transportation Science \& Techno logy, 2003(4):78 80

[8] Laura D.Marlino. REPORT ON TOYOTA PRIUS MOTOR THERMAL MANAGEMENT. Oak Ridge National Laboratory, 2005.

[9] Aymeric Rousseau.PAST Help Document. Argonne National Laboratory.2002,2.

[10] Yanlu,Hu Yuli. Influence on Efficiency of Permanent Magnet Direct Current Motor Caused by the Rise of Temperature.[J] Micromachine,2007(4):58 60 